\title{
Other minds in the brain: a functional imaging study of "theory of mind" in story comprehension
}

\author{
P.C. Fletcher ${ }^{a, c}$, F. Happéb, U. Frith ${ }^{\text {b.d.* }}$, S.C. Baker ${ }^{a}$, \\ R.J. Dolan ${ }^{a, c}$, R.S.J. Frackowiak ${ }^{a}$, C.D. Frith ${ }^{\text {a d } * *}$ \\ "Wellcome Department of Cognitive Neurology, Institute of Neurology, 12 Queen Square, \\ London WCIN $3 B G, L K$ \\ ${ }^{\mathrm{b}} M R C$ Cognitive Development Unit, 4 Taviton Street, London WCIH OBT, UK \\ "Royal Free Hospital Medical School, Roland Hill St. London NW3, UK \\ "Department of Psychology, University College London, Gower St, London WC1E 6BT, UK
}

Received October 20, 1995, final version accepted August 16, 1995

\begin{abstract}
The ability of normal children and adults to attribute independent mental states to self and others in order to explain and predict behaviour ("theory of mind") has been a focus of much recent research. Autism is a biologically based disorder which appears to be characterised by a specific impairment in this "mentalising" process. The present paper reports a functional neuroimaging study with positron emission tomography in which we studied brain activity in normal volunteers while they performed story comprehension tasks necessitating the attribution of mental states. The resultant brain activity was compared with that measured in two control tasks: "physical" stories which did not require this mental attribution, and passages of unlinked sentences. Both story conditions, when compared to the unlinked sentences, showed significantly increased regional cerebral blood flow in the following regions: the temporal poles bilaterally, the left superior temporal gyrus and the posterior cingulate cortex. Comparison of the "theory of mind" stories with "physical" stories revealed a specific pattern of activation associated with mental state attribution: it was only this task which produced activation in the medial frontal gyrus on the left (Brodmann's area 8). This comparison also showed significant activation in the posterior cingulate cortex. These surprisingly clear-cut findings are discussed in relation to previous studies of brain activation during story comprehension. The localisation of brain regions involved in normal attribution of mental states and contextual problem solving is feasible and may have implications for the neural basis of autism.
\end{abstract}

* Authors to whom correspondence should be addressed. 


\section{Introduction}

Our ability to explain and predict the behaviour of others in terms of their mental states (beliefs and desires) has been referred to as "theory of mind" (Premack \& Woodruff, 1978) or "mentalising" (Frith, Morton, \& Leslie, 1991). This way of making sense of behaviour appears to be both useful and ubiquitous. Just as we perceive certain patterns of movement in terms of physical causation (Leslie \& Keeble, 1987), so we cannot help but perceive certain behavioural interaction patterns in terms of intention (Premack 1990; Leslie \& Roth, 1993; Dasser, Ulbaek, \& Premack, 1989). So, for example, under certain conditions a hand movement will be perceived as a pointing gesture (expressing the intention to direct another's attention), under other conditions as a wave or a swipe at a fly.

In the light of its apparent evolutionary advantages, it is plausible that mentalising is performed by an innately determined cognitive mechanism (Leslie, 1987, 1994; Leslie \& Roth, 1993). The developmental sequence is culturally invariant (Avis \& Harris, 1991) and relatively independent of the level of intelligence (Nunez \& Riviere, 1990), with little individual variation and a strikingly narrow time window (Happé, 1995). Additional evidence that this ability is biologically based comes from a consideration of autism (Frith et al., 1991). Autism appears to be characterised by a lack of theory of mind ("mentalising") (Leslie, 1987; Frith, 1989; Baron-Cohen, TagerFlusberg, \& Cohen, 1993). Children and adults with autism typically fail false belief tasks (Baron-Cohen, Leslie, \& Frith, 1985) and the core social impairments shown by autistic individuals can be readily explained by a failure to represent the thoughts and feelings of others (Frith, 1989). While most individuals with autism are of low IQ, autism can also occur in conjunction with normal or even superior intelligence (Rumsey \& Hamburger, 1988). This latter finding suggests that the theory of mind deficit is highly specific: genetic or metabolic effects may damage the brain substrates of mentalising without compromising other functions (Frith et al., 1991; Happé \& Frith, 1994).

The theory of mind account has made successful predictions about reallife abilities and deficits. For example, children with autism can use gestures to direct behaviour (e.g., "come here", "go away" gestures), but not to affect internal/mental states (e.g., gestures of affection or consolation) (Attwood, Frith, \& Hermelin, 1988). They can also, when taught, engage in fixed small talk, but are unable to conduct a flexible conversation taking into account the interests of others (Frith, Happé, \& Siddons, 1994). The distinction between intact and impaired abilities in autism has been demonstrated in many studies, some of which are summarised in Table 1. The "fine cuts" approach, reflected in this table, seems particularly well suited to the positron emission tomography (PET) scan method of functional neuroimaging in which different cognitive functions must be contrasted using otherwise similar tasks. 
Table 1

Autistic assets and deficits as predicted by the "fine cuts" technique, between tasks which require mentalising and those which do not

\begin{tabular}{|c|c|}
\hline Assets & Deficits \\
\hline Ordering behavioural pictures & $\begin{array}{l}\text { Ordering mentalistic pictures } \\
\text { (Baron-Cohen, Leslie, \& Frith, 1986) }\end{array}$ \\
\hline Understanding see & $\begin{array}{l}\text { Understanding know } \\
\text { (Perner, Frith, Leslie, \& Leekam, 1989; } \\
\text { Leslie \& Frith. 1988) }\end{array}$ \\
\hline Protoimperative point & $\begin{array}{l}\text { Protodeclarative pointing } \\
\text { (Baron-Cohen. 1989) }\end{array}$ \\
\hline Sabotage & $\begin{array}{l}\text { Deception } \\
\text { (Sodian \& Frith, 1992) }\end{array}$ \\
\hline False photographs & $\begin{array}{l}\text { False beliefs } \\
\text { (Leslie \& Thaiss, 1992; } \\
\text { Leekam \& Perner. 1991) }\end{array}$ \\
\hline Recognising happiness and sadness & $\begin{array}{l}\text { Recognising surprise } \\
\text { (Baron-Cohen, Spitz, \& Cross, 1993) }\end{array}$ \\
\hline Object occlusion & $\begin{array}{l}\text { Information occlusion } \\
\text { (Baron-Cohen, 1992) }\end{array}$ \\
\hline Literal expression & $\begin{array}{l}\text { Metaphorical expression } \\
\text { Happé. 1993) }\end{array}$ \\
\hline
\end{tabular}

Some individuals with autism, in particular, more intelligent adults, do pass simple tests of theory of mind, normally passed at the age of 4 years (Baron-Cohen, 1989; Bowler, 1992; Ozonoff, Pennington, \& Rogers, 1991), but have problems with mentalising at higher levels. Recently, Happé tested able autistic children and adults with a set of stories requiring the attribution of complex mental states (e.g., double bluff, white lie, persuasion) (Happé, 1994). Subjects read these stories and answered questions about them. In their answers, these able autistic individuals made striking errors, misunderstanding protagonists' intentions. Thus, unlike mentally handicapped or young normal subjects, autistic subjects, even of normal IQ, confused, for example, a lie with a joke, or persuasion with misunderstanding. Errors in mental state attribution were only found in autistic subjects, and were sufficient to discriminate even those subjects who passed standard false belief tasks. By contrast, autistic subjects had no difficulty in understanding the physical events in the stories, or stories not involving mental states.

Of the various tests validated with autistic subjects, Happé's stories seemed best suited to the constraints of functional imaging. They are suitable for adults and allow systematic manipulation of the extent to which they require the consideration of motivation and intention. They may be presented in written form, reading being a cognitive function which has been extensively studied with PET. They are easily adapted to the constraints of scanning time requirements (one story taking approximately 30 seconds to read). Unfortunately, the control stories used in the Happé study were 
unsuitable for our purposes, since her results showed that they were not equated for difficulty with the theory of mind stories. Two new types of control condition were therefore designed for the present study: "physical stories" and "unlinked sentences".

The physical stories were constructed to parallel the theory of mind stories in requiring inference beyond the information stated. They both shared the requirement to integrate information from the constituent sentences into a story structure, to remember and link events and to infer an implicit element. However, while both types of stories involved people, the physical stories did not require or invite consideration of their mental states. Our aim was that these two conditions should differ only in a requirement for mentalising and we made sure that our subjects understood this distinction through practice tasks. Our second control task, "unlinked sentences", was constructed from sentences taken at random from different prose passages. This condition contrasts with both story types in not requiring integration of material into a story structure, and not requiring inference. However, it required, in common with the other conditions, reading, attention to sentence meaning, memory and (silent) question answering.

Our study aimed, then, to locate areas of the brain in which there was activity specifically associated with the process of mentalising in normal subjects. Functional brain activation studies of this type provide an alternative and promising way of investigating the abnormalities of brain function that result in autism. In a recent review, Horwitz and Rumsey (1994) concluded that resting PET scan studies have been inconclusive and failed to pinpoint any abnormalities specific to the brains of people with autism. Likewise, reviews of other evidence from neuropathology, neurophysiology and neurochemistry demonstrate that even positive findings (e.g., cerebellar and limbic system abnormalities at the level of neural density) cannot be interpreted as autism-specific because of lack of adequate controls and failure to replicate (Bauman \& Kemper, 1994). Locating brain regions implicated in the normal attribution of mental states should help to isolate putative sites of damage or dysfunction specific to the psychopathology of "mind-blind" autistic people. Before attempting to use functional imaging to localise the pathway at fault in autism, it is first vital to validate our experimental technique with normal subjects.

\section{Materials and methods}

\subsection{Subjects}

Six right-handed male volunteers (age range 24-65 years; average 38 years) took part in this study, which was approved by the Hammersmith Hospital Ethics Committee and the Administration of Radioactive Sub- 
stances Advisory Committee (ARSAC). All subjects gave written, informed consent. All subjects were fit, healthy and free of any significant previous or current medical, psychiatric or neurological illness.

\subsection{Positron emission tomography scanning}

Scans of regional cerebral blood flow (rCBF) were obtained using a CTl model 953B-PET scanner (CTI, Inc., Knoxville, USA) with collimating septa retracted. Subjects received a 20 -second intravenous bolus of $\mathrm{H}_{2}{ }^{15} \mathrm{O}$ at a concentration of $55 \mathrm{mBq} \mathrm{ml} \mathrm{m}^{-1}$ and a flow rate of $10 \mathrm{ml} \mathrm{min}^{-1}$ through a fore-arm cannula. Twelve dynamic PET scans were collected, each over a period of 2.5 minutes, beginning 0.5 minutes before the delivery of the bolus. The integrated radioactivity counts accumulated over the acquisition period were used as an index of rCBF. Subjects were scanned in a quiet. darkened room. There was a 10-minute gap between each scan.

\subsection{Tasks}

Three types of passage were presented: "theory of mind stories" (ToMS), "physical stories" (PS) and "unlinked sentences" (US). Examples of these are given in the Appendix.

This material was validated with 60 normal subjects of a similar age (16-55 years) and educational level as our PET scan volunteers. Subjects were given examples of the three types of story at the beginning of the session. The stories and unconnected sentences were then presented, one per page, in random order. Subjects were instructed to read each passage silently and turn over the page as soon as they finished. Page turning was the signal for the experimenter to stop timing. The next page posed a question about the story which the subject had to answer.

The "theory of mind" texts were read slightly, but significantly, faster (mean 25 seconds, $S D$ 7.9) than the "physical" texts (mean 30 seconds, $S D$ 9.5 ) and the unlinked sentences (mean 28 seconds, $S D$ 9.1). The answers to the questions were scored as 0 for wrong, 1 for implicitly or partially correct, 2 for elaborate and explicitly correct. For the unconnected sentences, the answers were scored either 0 for incorrect or 2 for correct, as there was no intermediate possibility. There was thus a maximum of 16 for each condition. The results showed that there were no differences between the three conditions in accuracy of answers. Mean scores were: ToMS 12.9 (SD 1.9), PS 12.8 ( $S D 2$ ), US 12.2 ( $S D 2.8$ ). We therefore considered the three tasks to be of equal difficulty. Importantly, for the logic of subtraction which underlies the experimental design, the task which had the extra requirement of mentalising was the fastest rather than the slowest.

During scanning, the passages were presented on the screen of a Macintosh LC II personal computer suspended on a cradle approximately 2 feet from the subjects. Prior to scanning, the experimenter ascertained that 
the subject could read them comfortably. The subject was asked to read the passage silently, once at his own pace. Having done this, he touched the screen with his right hand. This caused the passage to be replaced by a question which he was instructed to answer silently. Having done this, he touched the screen again and a second passage of prose appeared which in turn was followed by a question. The total time taken to read a passage and answer its question was recorded for each of the two passages seen during the scan. After the scan had finished, the subject's answers for the two passages were recorded.

At the beginning of the session, subjects were briefed about the types of problem to be solved and given short examples. It was explained that, in ToMS stories, it was vital to consider the thoughts and feelings of the characters, while, in the other passages (PS and US), this was not only irrelevant but undesirable. In the non-story condition (US), they were asked not to try to make coherent sense of the passage. Prior to each scan, subjects were told which type of passage they would see. Within any scan, two passages of the same type were presented. The order of tasks was counterbalanced rather than randomised in order to avoid variable order artefacts due to the small number of subjects studied. Each of the three tasks was administered four times over the course of the 12 scans in an $\mathrm{ABC}$ counterbalanced design.

We predicted that a comparison of those scans in which the subject performed a ToMS task with those in which he performed a US task would identify brain areas involved in understanding a story which required attribution of mental states. Similarly, comparison of PS with US scans would show areas engaged by processing a story that did not involve attribution of mental states. Finally, comparison of the ToMS and PS would isolate those areas uniquely involved in the attribution of mental states.

\subsection{Data analysis}

Each reconstructed rCBF scan, consisting of 31 primary transverse planes, was interpolated to 43 planes to render the voxels approximately cubic. Subsequently, the total set of scans was realigned so that all 12 scans of each subject were in register (AIR software) (Woods, Cherry, \& Mazziota, 1992). The data were subsequently transformed into a standard stereotactic space (Talairach \& Tournoux, 1988; Friston et al., 1989). Such transformation of the scans allows for pixel-by-pixel averaging of data across subjects in the standard space. A Gaussian filter (full width at half maximum $20 \mathrm{~mm}$ ) was applied at this stage to smooth each image in order to accommodate inter-subject differences in gyral and functional anatomy and to suppress high-frequency noise.

Differences in global activity within and between subjects were removed by analysis of covariance (Wildt \& Ahtola, 1978) generating a conditionspecific adjusted mean rCBF value (normalised to $50 \mathrm{ml} \mathrm{dl}^{-1} \mathrm{~min}^{-1}$ ) and an 
associated adjusted error variance. This allowed comparison of the means across all sets of conditions using the $t$ statistic. The resulting set of $t$ values constitutes a statistical parametric map $(\operatorname{SPM}(t))$ (Friston, Frith, Liddle, \& Frackowiak, 1991). Only pixels showing a change significant at the level of $p<.001$ were selected since this level of significance has been found to protect adequately against false positives with our equipment (Bailey, Jones, Friston, Colebatch, \& Frackowiak, 1991). In fact, the majority of activations seen in this study would survive a planewise correction for multiple nonindependent comparisons at $p<.05$ ( $Z$ score threshold approximately 3.8).

Image analysis was performed using SPM software (MRC Cyclotron. London, UK (Frackowiak \& Friston, 1994) on a SPARC 1 workstation (Sun Microsystems Inc., Surrey, UK) using an interactive image analysis software package (ANALYZE, Biodynamic Research Unit, Mayo Clinic, USA (Robb \& Hanson, 1991). Calculations and image matrix manipulations were performed in PRO MATLAB (Mathworks Inc., New York).

\section{Results}

\subsection{Task performance}

The times taken to perform the tasks are summarised in Table 2. Subject's responses to each of the questions were collected in the interval before the next scan. Across all of the theory of mind stories, the subjects answered satisfactorily referring to the mental states of the characters, indicating that they were engaging in mentalising in order to make sense of the stories.

Reference was made to a mental state (in each case, to a desire of a character in the story) in only three of the 48 instances when subjects were presented with a "physical" story. As in the theory of mind task, performance was at an extremely high level: in the former task, all questions were answered correctly; in the latter, 47/48 answers were correct.

On average, subjects gave 5.3 out of 8 correct answers on the unlinked sentences task (total 31.8/48). No mental state terms were used by subjects in giving these answers.

Table 2

Performance times

\begin{tabular}{lllll}
\hline Task & Mean & $S D$ & Range & Errors \\
\hline $\begin{array}{l}\text { Theory of } \\
\text { mind stories }\end{array}$ & 34 & 11.3 & $21-49$ & 0.0 \\
$\begin{array}{l}\text { Physical } \\
\text { stories }\end{array}$ & 35.3 & 8.3 & $23-44$ & 0.2 \\
$\begin{array}{l}\text { Unlinked } \\
\text { sentences }\end{array}$ & 32.7 & 6.4 & $23-39$ & 2.7 \\
\hline
\end{tabular}




\subsection{PET results}

\subsubsection{ToMS versus US tasks}

This comparison showed that four separate regions were activated by the "theory of mind" stories to a significantly greater extent than when the subjects read a passage of unlinked sentences. The activated regions were the temporal poles bilaterally, the left superior temporal gyrus, the posterior cingulate cortex and the left medial frontal gyrus (see Fig. 1).

\subsubsection{PS versus US}

This comparison showed three of the areas of activation found in the ToMS versus US comparison, namely the temporal poles bilaterally, the left
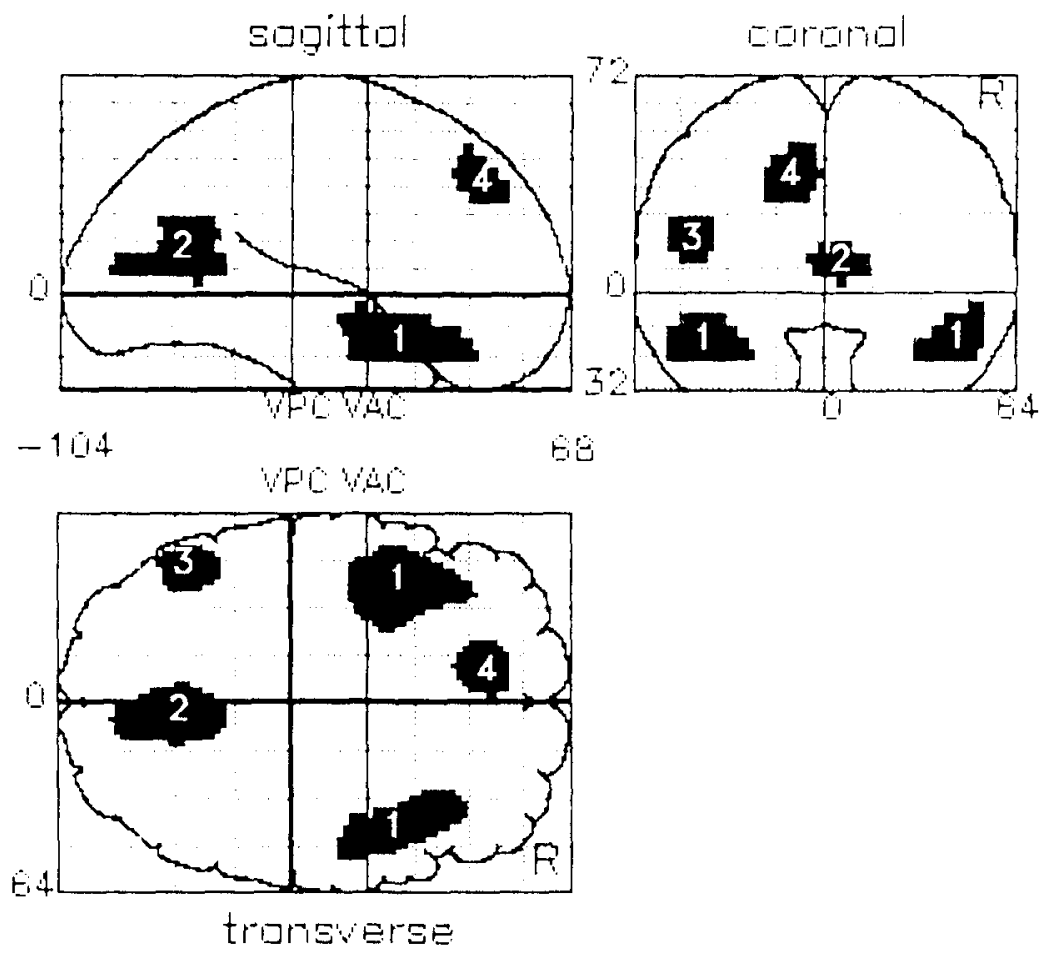

Fig. 1. Statistical parametric maps (SPMs) of the comparison of the theory of mind task with the unlinked sentences task. (A further Gaussian filter $(8 \mathrm{~mm}$ full width at half maximum) was applied at the stage of computation of statistical parametric maps to increase the signal-to-noise ratio in the data set). Views are shown from the right (labelled "sagittal"), behind ("coronal") and above ("transverse"). Activations significant (at $p<.001)$ are shown in the temporal poles bilaterally (1), the posterior cingulate cortex (2), the left superior temporal gyrus (3) and the left medial frontal gyrus (4). 
superior temporal gyrus and the posterior cingulate cortex. Strikingly, there was no activation of the left medial frontal gyrus (see Fig. 2).

\subsubsection{ToMS versus $P S$}

This comparison showed activation in the left medial frontal gyrus, predominantly Brodmann's area 8 , extending posteriorly into area 9 and the anterior cingulate cortex. There was additional activation in the posterior cingulate cortex and inferior parietal lobe on the right (see Fig. 3).

In order to ascertain that there was no subthreshold activation of the left medial frontal gyrus in association with the PS task, we re-examined this comparison at a lower threshold $(p<.05$ not corrected for multiple comparisons). No activation was seen relative to the US task. We also examined $\mathrm{rCBF}$ equivalents for the pixel of maximal activation. Again, there was no evidence of any activation in this region in the PS task ( $\mathrm{rCBF}=54.4 \mathrm{ml} \mathrm{dl}^{-1} \min ^{-1}$ as compared to $54.4 \mathrm{ml} \mathrm{dl}^{-1} \min ^{-1}$ for the US
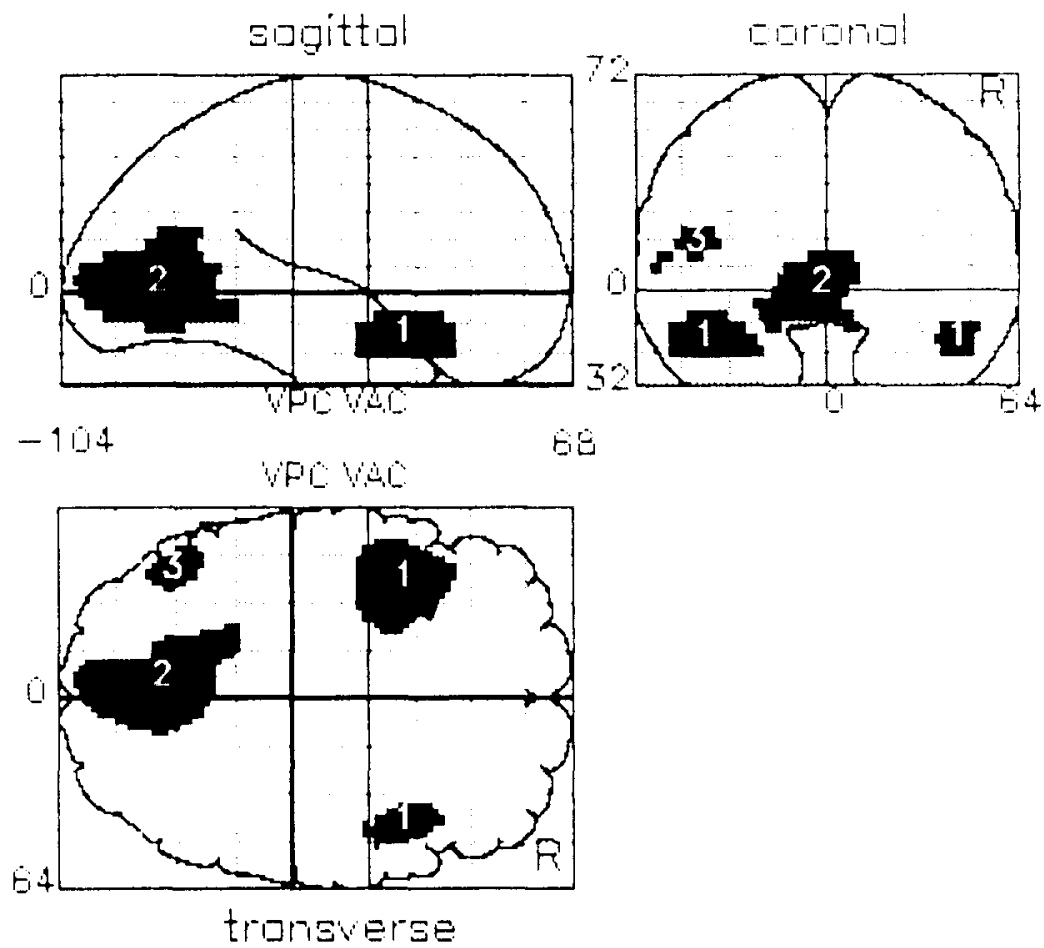

Fig. 2. SPMs presented as for Fig. 1 showing activations in the comparison of the physical story with the unlinked sentences. Here activations are seen in the temporal poles bilaterally (1), the posterior cingulate cortex (2) and the left superior temporal gyrus (3), but not the left medial frontal gyrus. 

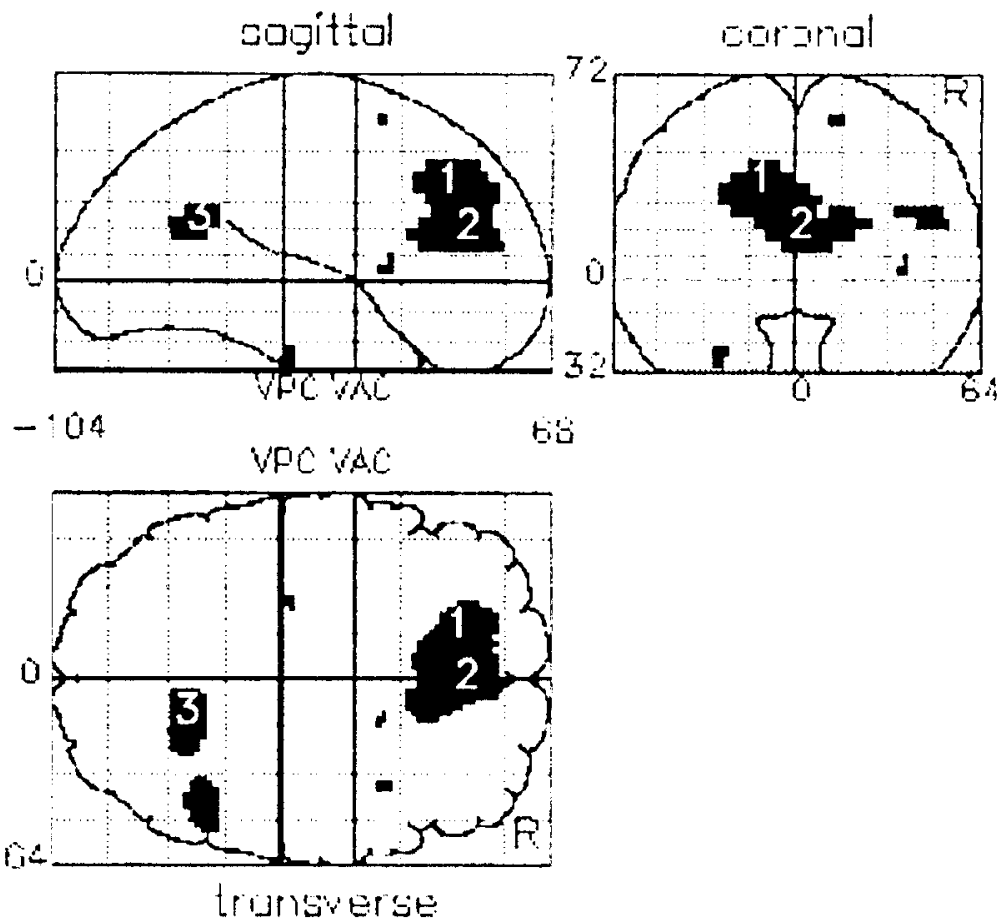

Fig. 3. SPM showing a direct comparison between the theory of mind and the physical task. The main area of difference between the two types of story is the left medial frontal region (1), with a small difference in activation in the anterior (2) and posterior cingulate cortex (3).

task and $55.3 \mathrm{ml} \mathrm{dl}^{-1} \mathrm{~min}^{-1}$ for the ToMS task). The results are summarised in Table 3.

\subsubsection{US versus (ToMS + PS)}

This comparison, indicating brain areas more active during the unlinked sentences task, showed activation of the prefrontal cortex, predominantly on the right, and posterior parietal areas, notably the precuneus (Brodmann's area 7 ). Results are summarised in Table 4.

\section{Discussion}

Our experiment allows us to make the surprising inference that the attribution of mental states is particularly associated with the function of a highly circumscribed brain system.

We have used an experiment that involves reading and understanding prose passages, some of which involved the attribution of mental states while others required only a logical understanding of the sense of the story 


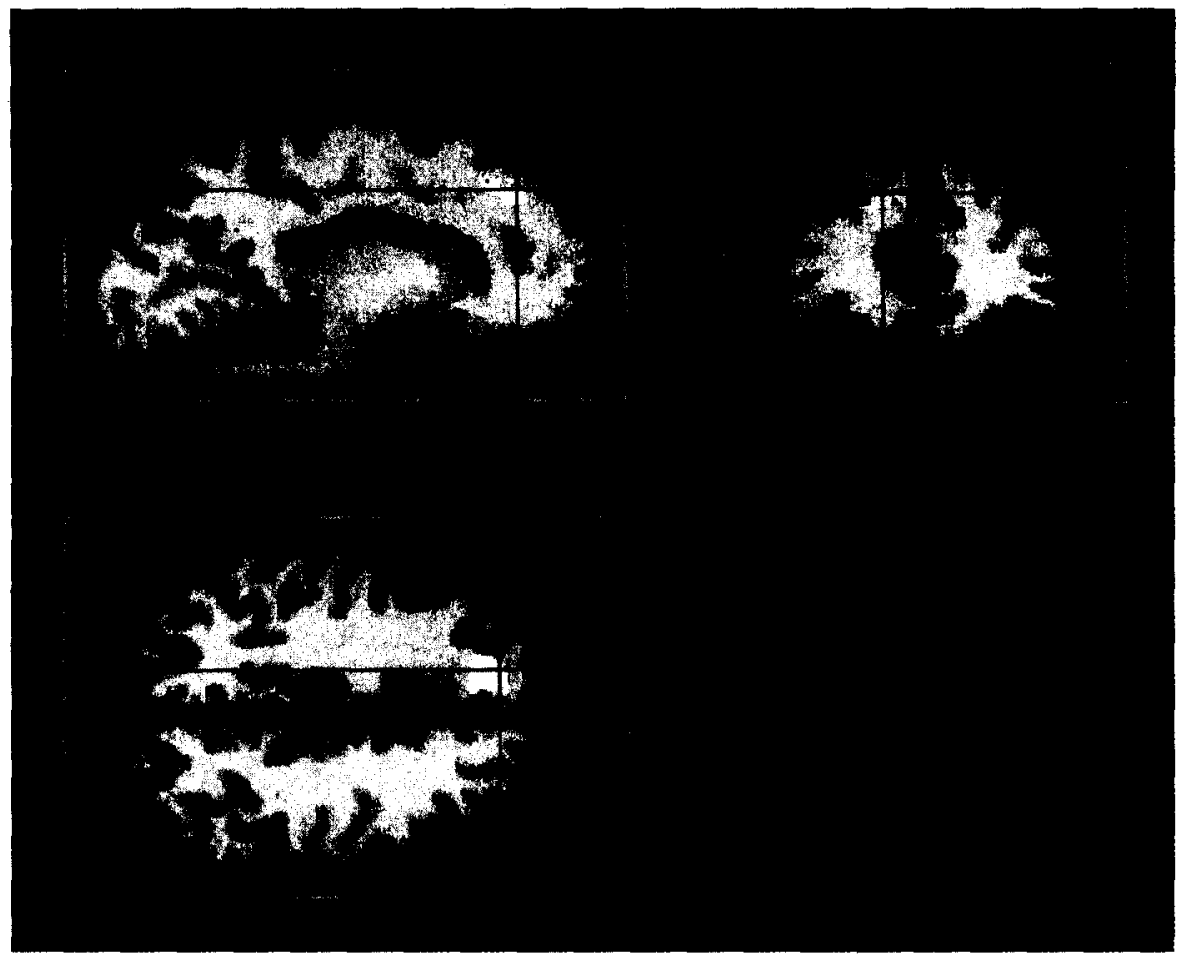

Fig. 4. The left medial frontal activation (from the ToMS vs. PS comparison) has heen superimposed onto a magnetic resonance image rendered into standard stereotactic space in order to give an indication of the area of activity to brain structure. In order to facilitate superimposition of the activation, a different analysis of the comparison was made in which a secondary smoothing filter was not used. The purpose of this figure is simply to help anatomical orientation to readers unfamiliar with SPM presentations in Figs. 1-3.

without reference to the mental states of the characters. Identification of areas concerned with the processing of stories was possible because we used a control task which consisted of individually meaningful but overall unconnected sentences.

There were three areas common with the mentalising and non-mentalising story tasks: the temporal poles bilaterally, the left superior temporal gyrus and the posterior cingulate cortex. Uniquely activated in the theory of mind task was the medial frontal gyrus, together with a portion of the posterior cingulate gyrus. All the areas where we found significant activation have shown activation in previous PET studies involving verbal memory, language and story comprehension (see below).

Only the mental state stories, in contrast to both control tasks, caused activation in the left medial frontal gyrus (Brodmann's area 8). This result closely resembles that of Mazoyer et al. (1993) in which listening to stories produced, in addition to temporal pole and superior temporal activation (see 
Table 3

Increases in brain activity associated with story comprehension

\begin{tabular}{lll} 
Region & \multicolumn{2}{l}{ Coordinatesa } \\
$x$ & $y$ & $Z$ value \\
\hline
\end{tabular}

Theory of mind stories

vs. unlinked sentences

L. medial frontal gyrus

(BA 8)

L. temporal pole (BA 38)

R. temporal pole (BA 38)

R. posterior cingulate cortex (BA 23/31)

L. superior temporal gyrus (BA 22/39)

$\begin{array}{rrrr}-12, & 42 & 40 & 4.8 \\ -44, & 20, & -16 & 4.9 \\ 44, & 18, & -16 & 5.3 \\ 4, & -64, & 12 & 4.8 \\ -44, & -58 & 20 & 4.2\end{array}$

Physical stories vs. unlinked sentences

L. temporal pole (BA 38

-40 ,

40, 16

16, $\quad-12$

4.7

R. temporal pole (BA 38)

-2 ,

$-16$

4.3

L. posterior cingulate

$-62$

4.8

cortex (BA 23/31)

L. superior temporal

-42 ,

-64 ,

3.6

gyrus (BA 22/39)

Theory of mind stories

vs. physical stories

L. medial frontal gyrus

(BA 8)

R. posterior cingulate

(BA 23/31)

Anterior cingulate (BA 32)

R. inferior parietal (BA 40)

$\begin{array}{rrrr}-12, & 36, & 36 & 4.1 \\ 6, & -56, & 16 & 3.6 \\ 0, & 38, & 24 & 3.7 \\ 42, & -50, & 24 & 3.5\end{array}$

"Coordinates are given with reference to a standard stereotactic space (Talairach \& Tournoux. 1988).

Table 4

Decreases in brain activity associated with story comprehension

\begin{tabular}{|c|c|c|c|c|}
\hline \multirow[t]{2}{*}{ Region } & \multicolumn{3}{|c|}{ Coordinates" } & \multirow[t]{2}{*}{$Z$ value } \\
\hline & $x$ & $y$ & $z$ & \\
\hline \multicolumn{5}{|l|}{$\begin{array}{l}\text { Unlinked sentences vs. } \\
\text { stories }\end{array}$} \\
\hline $\begin{array}{l}\text { R. middle frontal gyrus } \\
\text { (BA 46) }\end{array}$ & 36 & 30 & 28 & 6.6 \\
\hline $\begin{array}{l}\text { L. middle frontal gyrus } \\
\text { (BA 10) }\end{array}$ & -32 & 50 & 20 & 3.9 \\
\hline R. precuneus (BA 31/7) & 8 & -74 & 36 & 4.1 \\
\hline L. precuneus (BA 31/7) & -14 & -66 & 36 & 4.2 \\
\hline $\begin{array}{l}\text { Anterior cingulate } \\
\text { cortex (BA 32) }\end{array}$ & 0 & 16 & 40 & 4.7 \\
\hline
\end{tabular}


below), activation in an area referred to as the left superior prefrontal region corresponding to Brodmann's area 8 . Although the authors were not specifically concerned with the content of the stories used, subsequent inspection of their materials showed that both test stories involved complex social interaction (e.g., competition, deception, intrigue), and necessitated the attribution of higher-order mental states to the story characters (Mehler, personal communication).

One previous study in which functional brain imaging was used to investigate theory of mind has recently been reported (Baron-Cohen et al., 1994). Targeting the orbitofrontal regions, this study used a different task (discriminating words which described mental states from those which did not), a different, less sensitive methodology (single-proton emission computer tomography: SPECT) and a more limited type of image analysis (a "regions of interest" approach applied to the frontal cortex). This study found different activation patterns relating to the orbitofrontal regions only. In our study, we found no significant differences in activity in this region. Instead, our data pinpointed the medial dorsal region of the left frontal cortex as being critically involved in mentalising.

Functions of the medial frontal region in humans have not been well documented. It has been regarded as a transitional region between the premotor area and the dorsal prefrontal cortex (Brodmann's areas 6 and 9/46 respectively). It has widespread cortical connections including parietal (Petrides \& Pandya, 1984), temporal polar (Moran. Mufson, \& Mesulam, 1987), occipital and anterior cingulate cortex (Pandya, Van Hoesen \& Mesulam, 1981). Lesions to the region produce deficits in conditional learning in monkeys (Petrides, 1982) and humans (Petrides, 1990). A recent functional imaging study showed activation of this region in association with a conditional associative learning task. In this task, the correct response (pointing to one symbol from a choice of eight) was dependent upon the colour of a stripe at the top of the display (Petrides, Alivisatos, Evans, \& Meyer, 1993). One possible, but tenuous, explanation for the occurrence of medial frontal activation in our theory of mind tasks and the conditional task of Petrides is that the tasks share the need for integration of information in the light of other stimuli. For instance, in our example story (see Appendix), the policeman's request for the burglar to stop, in the context of the story, has very different implications from its usual meaning. Interestingly, a claim for a connection between conditional reasoning and theory of mind skills has been made (Frye, Zelazo, \& Palfai, 1994).

In the direct comparison between the ToMS and PS tasks, two additional areas were identified: anterior cingulate and inferior parietal cortex. However, since these areas did not appear in the comparisons of the ToMS tasks with the US task, we cannot assume that they have a specific association with mentalising abilities.

Bilateral activation of the temporal poles, the anterior-most part of the temporal lobes, corresponding to Brodmann's area 38 , was a significant 
finding for both types of story. Animal work has shown the temporal poles to receive inputs mainly from the orbitofrontal cortex, the medial frontal region and other areas of the temporal lobes including the medial temporal lobe structures and the superior temporal gyrus (Moran et al., 1987). Our finding of concurrent activation of two of these areas (the medial frontal region and the superior temporal gyrus) is consistent with these anatomical links. In humans, it has been shown that lesions to the left temporal pole cause impairment in the recall of stories (spoken or written) in the presence of normal comprehension of sentences and intact working memory (Milner, 1958; Frisk \& Milner, 1990) suggesting that this area is not involved in the comprehension of individual propositions, but in the concatenation of propositions to form a narrative.

Importantly, the brain regions significantly activated in our study were the same as those activated in the Mazoyer et al. study already mentioned. This is remarkable since, in the present study, subjects read the stories in silence, internally answering questions about them, while, in the French study, subjects only listened to stories and had no explicit task to perform. Their study identified regions activated when listening to stories in contrast to listening to incomprehensible speech (foreign language stories), single words, semantically anomalous sentences and sentences containing pseudowords. Significant activation of the temporal poles bilaterally was noted when subjects listened to the native language stories compared to all other tasks. They suggest that the left temporal pole may be concerned with memory for linguistic content and the right with encoding and storage of the pragmatic, prosodic and discursive aspects of the stories. Our own finding of increased bilateral temporal pole activity during the reading of stories, compared to unlinked sentences, is perhaps evidence against the involvement of this region in prosody. However, silent reading of narratives may activate prosodic aspects of language which are specific narrative rather than sentences. This suggests that these regions may be involved when a level of processing is required beyond that associated with the lexical and semantic analysis of individual words. Evidence for this also comes from strong left temporal pole activation in a PET study comparing the processing of sentences with that of random word strings (Bottini et al., 1994).

The left posterior superior temporal gyrus, corresponding to Brodmann's areas $22 / 39$, was also activated by both types of narrative when compared to unlinked sentences. As can be seen from Figs. 1 and 2 and Table 3, activation was in very similar areas in both cases. Activity in this area, it has been suggested, may be associated with sentence processing in humans (Mazoyer et al., 1993) and has been identified in rhesus monkeys as an important point of convergence (together with the frontal pole and the orbitofrontal context) of the intracortical sensory paths (Jones \& Powell, 1970). Of course, language function is unique to humans, which makes comparison with data from animal studies difficult. A number of human studies have associated lesions in this area with language deficits (Gesch- 
wind, 1965; Hart \& Gordon, 1990): Hart and Gordon, noting three patients with semantic comprehension deficits associated with lesions to the region, suggest that the anterior part of this area is concerned with "higher level elaboration" of auditory and visual information and the posterior superior part with "integration of this information with language". In several functional imaging studies, this region has shown activation notably in lexico-semantic processing (Peterson, Fox, Posner, Mintun \& Raichle, 1989; Démonet et al., 1992). Our own finding of superior temporal activation in both story conditions compared to unlinked sentences indicates a role in a higher level of language processing. that is. cohesion across sentence boundaries.

Activation of the posterior cingulate cortex, Brodmann's area 23/31, was also common to both story conditions when compared to unlinked sentences. This activation was significantly greater in the theory of mind stories than in the physical ones. The posterior cingulate gyrus is a region with widespread cortical connections, notably to the prefrontal and medial temporal regions, the inferior parietal lobe and the superior temporal sulcus (Pandya et al., 1981). Human studies have linked the area with memory function (Valenstein et al., 1987; Rudge \& Warrington, 1991). Further evidence for this role has come from functional imaging work (Grasby et al. 1993) and one recent study has suggested that this area is preferentially involved during the encoding stage of episodic memory (Shallice et al., 1994). It seems unlikely, prima facie, that a role in memory could account for the posterior cingulate activation in this study since, if anything, the control condition (unlinked sentences) is likely to place a greater load on memory function than either of the story conditions. However, the more coherent nature of the material presented in the story tasks may mean that the subject is more likely to try to encode relevant material on-line in order to maintain the cohesion of the narrative, and incorporate new information into the accumulating story structure. By contrast, in the unlinked sentences condition, material encountered early in the passage should not affect encoding of later material and subjects would be unable to predict which pieces of information should be memorised for question answering. Another explanation for the finding is the suggested involvement of this area in visual processes (Rudge \& Warrington, 1991). If the presentation of the stories (whether mentalising or non-mentalising) leads to more visual imagery than unlinked sentences, then we might expect to see increased activity in posterior cingulate cortex. However, both of these suggestions are post hoc attempts to explain this activation.

We will not comment on the relative activations in the unlinked sentences task except to say that the areas seen (bilateral frontal and posterior parietal/precuneus) have all been previously implicated in PET studies of memory (Grasby et al., 1993). Recently, it has been claimed that right frontal and precuneus activity are especially important at the retrieval stage (Shallice et al., 1994). The necessity, during the US task, of recalling 
disparate sentences rather than retaining the overall sense of the story could perhaps explain this finding. However, this, again, is a post hoc suggestion which the study was not designed to address.

To summarise, we have used PET to examine the neural correlates of an important facet of cognitive function: the ability to attribute mental states. We identified a circumscribed brain system the medial frontal gyrus on the left. Two directions for further research are clear. We need to replicate these findings with further groups of volunteers, particularly through tasks which engage theory of mind in different ways (e.g., silent animation rather than stories). Secondly, the paradigms can be applied to autistic (or Asperger's syndrome) subjects in future studies. In this way, we may be able to shed light on the physiological basis of the normal ability to attribute mental states, and on the brain pathways implicated in the autistic disorders.

\section{Appendix: examples of materials}

\section{Theory of mind stories}

A burglar who has just robbed a shop is making his getaway. As he is running home, a policeman on his beat sees him drop his glove. He doesn't know the man is a burglar, he just wants to tell him he dropped his glove. But when the policeman shouts out to the burglar, "Hey, you! Stop!", the burglar turns round, see the policeman and gives himself up. He puts his hands up and admits that he did the break-in at the local shop.

Subject touches screen, story disappears, question appears:

Q: Why did the burglar do this?

Subject internally answers question and touches screen, whereupon second story appears:

During the war, the Red army capture a member of the Blue army. They want him to tell them where his armies' tanks are. They know that they are either by the sea or in the mountains. They know that the prisoner will not want to tell them, he will want to save his army, and so he will certainly lie to them. The prisoner is very brave and very clever, he will not let them find his tanks. The tanks are really in the mountains. Now when the other side ask him where his tanks are he says, "They are in the mountains."

Q: Why did the prisoner say that? 


\section{Physical stories}

A burglar is about to break into a jewellers" shop. He skilfully picks the lock on the shop door. Carefully he crawls under the electronic detector beam. If he breaks this beam it will set off the alarm. Quietly he opens the door of the store-room and sees the gems glittering. As he reaches out, however, he steps on something soft. He hears a screech and something small and furry runs out past him, towards the shop door. Immediately the alarm sounds.

Q: Why did the alarm go off?

Two enemy powers have been at war for a very long time. Each army has won several battles, but now the outcome could go either way. The forces are equally matched. However, the Blue army is stronger than the Yellow army in foot soldiers and artillery. But the Yellow army is stronger than the Blue army in air power. On the day of the final battle, which will decide the outcome of the war, there is heavy fog over the mountains where the fighting is about to occur. Low-lying clouds hang above the soldiers. By the end of the day the Blue army have won.

Q: Why did the Blue army win?

\section{Unlinked sentences}

The four brothers stood aside to make room for their sister, Stella. Jill repeated the experiment, several times. The name of the airport had changed. Louise uncorked a little bottle of oil. The two children had to abandon their daily walk. She took a suite in a grand hotel. It was already twenty years since the operation.

Q: Did the children take their walk?

One day Uncle Simon came to visit Alex. The first part of the performance had come to an end. He put away the letter and stuck his hands in his pocket. She was still holding her umbrella. The cats ran back to the boy. Flora came into the middle of the square. The little island had a high rocky shoreline.

Q: Did Flora go to the square?

\section{Acknowledgement}

This work was carried out at the MRC Cyclotron Unit, Hammersmith Hospital. We are extremely grateful for the use of these facilities. 


\section{References}

Attwood, A.H., Frith, U., \& Hermelin, B. (1988). The understanding and use of interpersonal gestures by autistic and Down's syndrome children. Journal of Autism and Developmental Disorders, 18, 241-257.

Avis, J, \& Harris, P.L. (1991). Belief-desire reasoning among Baka children: evidence for a universal conception of mind. Child Development, 62, 460-467.

Bailey, D., Jones, T., Friston, K.J., Colebatch, J.G., \& Frackowiak, R.S.J. (1991). Physical validation of statistical parametric mapping. Journal of Cerebral Blood Flow and Metabolism, 11, (Suppl. 2), S150 (Abstract).

Baron-Cohen, S. (1989). The autistic child's theory of mind: a case of specific developmental delay. Journal of Child Psychology and Psychiatry, 30, 285-298.

Baron-Cohen, S. (1992). Out of sight or out of mind? A naturalistic study of deception in autism. Journal of Child Psychology and Psychiatry, 33, 1141-1155.

Baron-Cohen, S., Leslie, A.M., \& Frith, U. (1985). Does the autistic child have a "theory of mind"? Cognition, 21, 37-46.

Baron-Cohen, S., Leslie, A.M., \& Frith, U. (1986). Mechanical, behavioural and intentional understanding of picture stories in autistic children. British Journal of Developmental Psychology, 4, 113-125

Baron-Cohen, S., Ring, H., Moriarty, J., Schmitz, B., Costa, D., \& Ell, P. (1994). The brain basis of theory of mind: the role of the orbito-frontal region. British Journal of Psychiatry, $165,640-649$.

Baron-Cohen, S., Spitz, A., \& Cross, P. (1993). Can children with autism recognize surprise? Cognition and Emotion, 7. 507-516.

Baron-Cohen, S., Tager-Flusberg, H., \& Cohen, D.J. (1993). Understanding other minds: Perspectives from autism. Oxford: Oxford University Press.

Bauman, M.L., \& Kemper, T.L. (1994). Neuroanatomical observations of the brain in autism. ln M.L. Mauman \& T.L. Kemper (Eds.), The neurobiology of autism (pp. 119-145). Baltimore: Johns Hopkins University Press.

Bottini, G., Corcoran, R., Sterzi, R., Paulesu, E., Schenone, P., Scarpa, P., Frackowiak, R.S.J., \& Frith, C.D. (1994). The role of the right hemisphere in the interpretation of figurative aspects of language. Brain, 117, 1241-1253.

Bowler, D.M. (1992). Theory of mind in Asperger's syndrome. Journal of Child Psychology and Psychiatry, 33, 877-893.

Dasser, V., Ulbaek, I., \& Premack, D. (1989). The perception of intention. Science, 243, 365-367.

Démonet, J.-F., Chollet, F., Ramsay, S., Cardebat, D., Nespoulous, J.-L., Wise, R., Rascol, A., \& Frackowiak, R.S.J. (1992). The anatomy of phonological and semantic processing in normal subjects. Brain, 115, 1753-1768.

Frackowiak, R.S.J., \& Friston, K.J. (1994). Functional neuroanatomy of the human brain: positron emission tomography - a new neuroanatomical technique. Journal of Anatomy, 184 211-225.

Frisk, V., \& Milner, B. (1990). The relationship of working memory to the immediate recall of stories following unilateral temporal or frontal lobectomy. Neuropsychologia, 28(2), $121-$ 135.

Friston, K.J., Frith, C.D., Liddle, P.f., \& Frackowiak, R.S.J. (1991). Comparing functional (PET) images: the assessment of significant change. Journal of Cerebral Blood Flow and Metabolism, 11, 690-699.

Friston, K.J., Passingham, R.E., Nutt, J., Heather, J.G., Sawle, G.V., \& Frackowiak, R.S.J. (1989). Localisation in PET images: direct fitting of the intercommisural (AC-PC) line. Journal of Cerebral Blood Flow and Metabolism, 9, 690-695.

Frith. U. (1989). Autism: Explaining the enigma. Oxford: Blackwell.

Frith, U., Happé, F., \& Siddons, F. (1994). Theory of mind and social adaptation in autistic, retarded and young, normal children. Unpublished manuscript. 
Frith, U., Morton, J., \& Leslie, A.M. (1991). The cognitive basis of a biological disorder: autism. Trends in Neuroscience, 14, 433-438.

Frye, D., Zelazo, P.D., \& Palfai, T. (1994). The cognitive basis of theory of mind. Unpublished manuscript.

Geschwind, N. (1965). Disconnection syndromes in animals and man. Brain, 88, 237-294.

Grasby, P.M, Frith, C.D., Friston, K.J.. Bench, C.F., Frackowiak, R.S.J., \& Dolan, R.J. (1993). Functional mapping of brain areas implicated in auditory-verbal memory function. Brain, $116,1-20$.

Happé, F.G.E. (1993). Communicative competence and theory of mind in autism: a test of relevance theory. Cognition, 48, 101-119.

Happé, F. (1994). An advanced test of theory of mind: understanding of story characters thoughts and feelings by able autistics, mentally handicapped and normal children and adults. Journal of Autism and Developmental Disorders, 24, 129-154.

Happé, F, (1995). The role of age and verbal ability in the theory of mind task performance of autistic subjects. Child Development, 66, 843-855.

Happé, F.. \& Frith. U. (1994). Theory of mind in autism. In E. Schopler \& G.B. Mesibov (Eds.), Learning and cognition in autism. New York: Plenum.

Hart, J. \& G Gordon, B. (1990). Delineation of single word semantic comprehension deficits in aphasia with anatomical correlation. Annals of Neurology, 27, 226-231.

Horwitz. B.. \& Rumsey, J.M. (1994). Positron emission tomography: implications for cerebral dysfunction in autism. In M.L. Bauman \& T.L. Kemper (Eds.), The neurobiology of autism (pp. 102-118). Baltimore: Johns Hopkins University Press.

Jones, E.G., \& Powell, T.P.S. (1970). An anatomical study of converging sensory pathways within the cerebral cortex of the rhesus monkey. Brain, 93, 793-820.

Leekam, S., \& Perner, J. (1991). Does the autistic child have a metarepresentational deficit? Cognition. 40, 203-218

Leslie, A.M. (1987). Pretense and representation: the origins of "Theory of Mind". Psychological Review, 94, 412-426.

Leslie, A.M. (1994). ToMM, ToBy and agency: core architecture and domain specifity, In L. Hirschfeld \& S. Gelman (Eds.). Domain specifty and cultural knowledge. Cambridge, UK: Cambridge University Press.

Leslie, A.M., \& Frith, U. (1988). Autistic children's understanding of seeing, knowing and believing. British Journal of Developmental Psychology, 4, 315-324.

Leslie, A.M., \& Keeble. S. (1987). Do 6-month-old infants perceive causality? Cognition. 25. 265-288.

Leslie. A. \& Roth, D. (1993). What autism teaches us about metarepresentation. In S. Baron-Cohen, H. Tager-Flusberg, \& D. Cohen (Eds.), Understanding other minds: Perspectives from autism (pp. 83-111). Oxford: Oxford University Press.

Leslie, A.M., \& Thaiss, L. (1992). Domain specificity in conceptual development: neuropsychological evidence from autism. Cognition, 4.3, 225-251.

Mazoyer, B.M., Tzourio. N., Frak. V., Syrota. A., Murayama, N., Levrier, O.. Salamon. G., Dehaene. S., Cohen. L.. \& Mehler, J. (1993). The cortical representation of speech. Journal of Cognitive Neurosicience. 5(4), 467-479.

Milner, B. (1958). Psychological defects produced by temporal lobe excision. Research Publication of the Association of Nervous and Mental Disorders, 36, 244-257.

Moran, M.A., Mufson. E.J.. \& Mesulam, M.-M. (1987). Neural inputs into the temporopolar cortex of the rhesus monkey. Journal of Comparative Neurology, 256, 88-103

Nunez, M.. \& Riviere. A. (1990). Theory of mind and other cognitive developments. Unpublished manuscript.

Ozonoff, S.. Pennington. B., \& Rogers, S. (1991). Executive function deficits in highfunctioning autistic children: relationship to theory of mind. Journal of Child Psychology and Psychiatry. 32, 1081-1106.

Pandya, D.N., Van Hoesen, G.W. \& Mesulam, M.-M. (1981). Efferent connections of the cingulate gyrus in the rhesus monkey. Experimental Brain Research. 42, 319-330. 
Perner, J., Frith, U., Leslie, A.M., \& Leekam, S.R. (1989). Exploration of the autistic child's theory of mind: knowledge, belief and communication. Child Development, 60, 689-700.

Peterson, S.E., Fox, P.T., Posner, M.I., Mintun, M., \& Raichle, M.E. (1989). Positron emission tomographic studies of the processing of single words. Journal of Cognitive Neurosciences, 1, 153-170.

Petrides, M. (1982). Motor conditional associative learning after selective prefrontal lesions in the monkey. Behavioural Brain Research, 5, 407-413.

Petrides, M. (1990). Non-spatial conditional learning impaired in patients with unilateral frontal but not unilateral temporal lobe excisions. Neuropsychologia, 28(2), 137-149.

Petrides, M., Alivisatos, B.. Evans, A.C., \& Meyer, E. (1993). Dissociation of human mid-dorsolateral from posterior dorsolateral frontal cortex in memory processing. Proceedings of the National Academy of Sciences USA, 90, 873-877.

Petrides, M., \& Pandya, D.N. (1984). Projections to the frontal cortex from the posterior parietal region in the rhesus monkey. Journal of Comparative Neurology, 228, 105-116.

Premack, D. (1990). Do infants have a theory of self-propelled objects? Cognition, 36, 1-16.

Premack, D., \& Woodruff, G. (1978). Does the chimpanzee have a theory of mind? Behavioural and Brain Sciences, 4, 515-526.

Robb. R.A., \& Hanson, D.P. (1991). A software system for interactive and quantitative visualisation of multi-dimensional biomedical images. Australasian Physical and Engineering Sciences in Medicine, 14, 9-30.

Rudge, P., \& Warrington, E.K. (1991). Selective impairment of memory and visual perception in splenial tumours. Brain. 114, 349-360.

Rumsey, J.M., \& Hamburger, S.D. (1988). Neuropsychological findings in high-functioning men with infantile autism, residual state. Journal of Clinical and Experimental Neuropsychology, 10, 201-221.

Shallice, T., Fletcher, P., Frith, C.D., Grasby, P.M., Frackowiak, R.S.J., \& Dolan, R.J. (1994). Brain regions associated with the acquisition and retrieval of verbal episodic memory Nature, 368. 633-635.

Sodian, B., \& Frith, U. (1992). Deception and sabotage in autistic, retarded and normal children. Journal of Child Psychology and Psychiatry, 33, 591-605.

Talairach, J., \& Tournoux, P. (1988). Co-planar stereotactic atlas of the human brain. Stuttgart: Thieme-Verlag.

Valenstein. E., Bowers, D., Mieke, V., Heilman, K.M., Day, A., \& Watson, R.T. (1987). Retrosplenial amnesia. Brain, 110, 1631-1646.

Wildt, A.R., \& Ahtola, O.T. (1978). Analysis of covariance: Sage University paper series on quantitative applications in the social sciences. Beverly Hills, CA: Sage.

Woods, R.P., Cherry, S.R., \& Mazziota, J.C. (1992). A rapid automated algorithm for accurately aligning and reslicing positron emission tomography images. Journal of Computer Assisted Tomography, 16, 620-633. 